\title{
18F-FDG PET/CT and COVID-19
}

\section{Beuy Joob ${ }^{1} \cdot$ Viroj Wiwanitkit ${ }^{2,3}$}

Received: 26 February 2020 / Accepted: 4 March 2020 / Published online: 12 March 2020

(C) Springer-Verlag GmbH Germany, part of Springer Nature 2020

Dear Sir,

we read the publication on "18F-FDG PET/CT findings of COVID-19: a series of four highly suspected cases" with a great interest [1]. Qin et al. noted that "Although 18F-FDG $\mathrm{PET} / \mathrm{CT}$ cannot be routinely used in an emergency setting and is generally not recommended for infectious diseases, our pilot data shed light on the potential clinical utility of this imaging technique in the differential diagnosis of complex cases [1]." We would like to share ideas and experience of this report In our countries, COVID-19 is seriously endemic. CT imaging is often used to evaluate lung problems. The gold standard for diagnosis of the infection is RT-PCR test. Chest CT might be useful for confirmation of diagnosis in suspected patients with COVID-19 [2]. There are different clinical findings in different stages of disease [3]. The 18F-FDG PET/CT it is still not recommended for diagnosis and 18F-FDG PET/ $\mathrm{CT}$ is more complex than classical Chest CT. The actual usefulness of 18F-FDG PET/CT should be further studied. There might also be a possible risk of disease spreading due to long period of 18F-FDG PET/CT procedure in investigation unit.

\section{Compliance with ethical standards}

Conflict of interest The authors declare that they have no conflict of interest.

\section{References}

1. Qin C, Liu F, Yen TC, Lan X. 18F-FDG PET/CT findings of COVID-19: a series of four highly suspected cases. Eur J Nucl Med Mol Imaging. 2020. https://doi.org/10.1007/s00259-02004734-w.

2. Fang Y, Zhang H, Xie J, Lin M, Ying L, Pang P, et al. Sensitivity of chest CT for COVID-19: comparison to RT-PCR. Radiology. 2020;19:200432. https://doi.org/10.1148/radiol.2020200432.

3. Pan F, Ye T, Sun P, Gui S, Liang B, Li L, et al. Time course of lung changes on chest CT during recovery from 2019 novel coronavirus (COVID-19) pneumonia. Radiology. 2020;13:200370. https://doi. org/10.1148/radiol.2020200370.

Publisher's note Springer Nature remains neutral with regard to jurisdictional claims in published maps and institutional affiliations.

This article is part of the Topical Collection on Letter to the Editor

Beuy Joob

beuyjoob@hotmail.com

Sanitation1 Medical Academic Center, Bangkok, Thailand

2 Dr DY Patil University, Pune, India

3 Hainan Medical University, Haikou, China 